\title{
EU NÃO SOU DE AÇO. EU SOU DE BAMBU. HIP-HOP, DESIGUALDADES DE GÊNERO E RESISTÊNCIA ${ }^{1}$
}

\author{
Paula Guerra ${ }^{2}$ \\ Sofia Sousa ${ }^{3}$
}

\section{Introdução}

As transformações que decorreram da Revolução de 25 de Abril de 1974 em Portugal, ainda hoje se fazem sentir. Contudo, devido à forte repressão junto das mulheres durante mais de quarenta anos, tópicos como a desigualdade de gênero no campo da criação e da produção artística e musical, são tão mais evidentes na atualidade (Guerra \& Sitoe, 2019). Já no contexto pós-revolução, no início da década de 1980, Portugal ainda se pautava por uma realidade homogénea, como uma sociedade fechada à diferença, sendo por isso importante perceber a génese deste movimento no país, ou seja, a chegada de uma cultura urbana, fruto de várias mudanças sociais, políticas, económicas e culturais, que aconteciam no restante mundo ocidental desde a década de 1970.

O principal foco deste artigo é o de perspetivar as produções de música rap por parte de artistas portuguesas, enquanto meio de denúncia das desigualdades de gênero, mas também de denúncia das dinâmicas urbanas segregadoras que, por sua vez, possuem influência nas desigualdades de gênero, bem como conduzem a configurações de afirmação pessoal e coletiva. Então, temos como base empírica, seis canções de artistas rappers portuguesas, sendo que nos iremos debruçar sobre as letras das canções, mas também sobre os videoclipes destas. Para cada artista, selecionámos uma canção. As artistas foram selecionadas pela sua relevância no panorama musical contemporâneo português: partimos de um conhecimento prévio, de outras investigações (Guerra, 2020; Sitoe \& Guerra, 2019; Sousa \& Guerra, 2021), que nos fez destacar estas artistas em detrimento de outras. Procurámos, então, apresentar, analisar e discutir estas canções e performances enquanto modos de protesto gentis e subtis (Corbett, 2018), tentando

\footnotetext{
1 Artigo realizado no âmbito do projeto "CANVAS - Towards Safer and Attractive Cities: Crime and

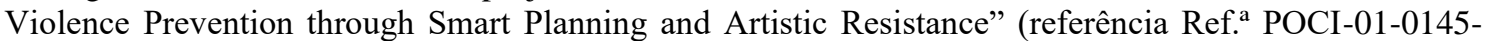
FEDER-030748) e do projeto "ArtCitizenship - Juventude e as artes da cidadania: práticas criativas, cultura participativa e activismo" (referência: Projeto/Contrato PS: 28655).

${ }^{2}$ Universidade do Porto, Faculdade de Letras, Porto, Portugal. Email pguerra@letras.up.pt. ORCID: https://orcid.org/0000-0003-2377-8045.

3 Universidade do Porto, Faculdade de Letras, Porto, Portugal. Email sofiaarsousa22@gmail.com. ORCID: https://orcid.org/0000-0002-3504-5394.
} 
aferir em que moldes estas canções e estas artistas refletem, silenciosamente e subtilmente, a sociedade de um país do Norte Global, bem como as implicações de se ser mulher e artista numa indústria segregadora.

Assim, os contributos de Soja (2010) são fulcrais. O autor introduz o conceito de geografias injustas que, na sua essência, traduz uma vasta gama de representações desigualitárias, e, por conseguinte, um lastro de espaços físicos delimitadores, podendo ir do corpo aos limites do planeta. Porém, seguindo a sua premissa, visámos enfatizar a dimensão urbana dessas geografias injustas, remetendo-nos para um conceito de periferização das cidades, mas também dos corpos e das práticas. Os espaços, como os bairros sociais, passam a serem tidos como espaços invisíveis, isto é, como não-lugares (Augé, 1994) que apenas se tornam visíveis quando neles acontecem motins ou revoluções. Pensando na representação das mulheres no hip-hop retomámos os contributos de Said (1979), pelo facto de referir que nenhum membro da cena hip-hop ser independente dos contextos geográficos e territoriais, daí que a noção de luta ou de resistência seja ampla e abrangente a várias dimensões da vida social destas artistas.

Ainda sobre as geografias injustas (Soja, 2010), na nossa pesquisa cotejámos que os estudos realizados sobre as representações e sobre a representatividade das mulheres no rap e no movimento hip-hop, em Portugal, apenas emergiram nos anos 2000, isto é, tardiamente face a outros países (Simões, 2019). Contudo, temas como a objetificação da mulher, os discursos misóginos, o machismo e a violência simbólica e por vezes física (Tavares, 2012; Oliveira, 2018; Samico, 2013), têm sido tópicos abordados e denunciados por este gênero musical, em Portugal, desde a década de 1990, por parte de artistas como Makkas ${ }^{4}$ ou Bambino ${ }^{5}$ (Simões, 2019). Do outro lado do mapa, no movimento de hip-hop norte-americano, artistas como Queen Latifah ${ }^{6}$, influenciam o

\footnotetext{
${ }^{4}$ Makkas é o nome artístico de Paulo Jorge Morais, ex-membro do grupo Black Company, criado na década de 1980 e da qual faziam parte rappers como Bantú e Bambino. Deste grupo fizeram parte vários artistas de renome, tais como General D. Mais informações em: https://www.muralsonoro.com/muralsonoro-pt/2014/10/20/makkas-rapper-black-company-the-raw-sample-project

${ }^{5}$ Rapper e ex-membro do grupo Black Company. Recentemente, em abril de 2021, lançou o seu single "Rap de Gente Grande". Mais informações em: https://www.rimasebatidas.pt/bambino-um-gajo-continuaa-tentar-ser-coerente-e-a-representar-a-old-school/

${ }^{6}$ É uma cantora, rapper, atriz, compositora, produtora de televisão, produtora musical, comediante e apresentadora norte-americana. Ela iniciou sua carreira artística como rapper, lançando seu primeiro álbum intitulado All Hail the Queen, em 1989. Em 1991, lançou seu segundo álbum Nature of a Sista. Seu primeiro papel como atriz foi em 1993, como Khadijah James na sitcom da FOX, Living Single. Seu terceiro álbum Black Reign (1993), gerou o single "U.N.I.T.Y.", que ganhou um Grammy e foi bem sucedido na Billboard Hot 100. Latifah começou como beatbox no grupo de hip-hop Ladies Fresh e também como uma das integrantes do Flavor Unit, que era um grupo de MC's produzidos e empresariados pelo DJ King Gemini. Em 1988, King produziu uma fita demo para Latifah, com uma
} 
surgimento dos primeiros grupos de rap feminino em Portugal: Djamal e Divine ${ }^{7}$. Estas artistas foram pioneiras e fizeram um sucesso desmedido entre os anos de 1989 e 1999 (Simões, 2019), principalmente por terem sido as primeiras a produzirem um álbum de originais, composto maioritariamente por mulheres afrodescendentes. Estas canções originais foram uma primeira demonstração das desigualdades associadas ao gênero, que ainda hoje podem ser mapeadas nas sociedades contemporâneas, pelas artistas que nos propusemos analisar.

\section{Cultura hip-hop: aproximação ao objeto de estudo}

Outrora, o movimento hip-hop era tendencialmente encarado como uma manifestação política e cultural, que consentia o surgimento de espaços criativos que, por sua vez, lutavam contra a opressão (Campos \& Simões, 2014; García \& Pàmplos, 2020; Librado, 2010). Alguns artigos (Simões et al., 2005; García \& Pàmplos, 2020; Mazer et al., 2018) têm salientado o hip-hop enquanto movimento cultural, remetendo-o à génese do seu aparecimento na década de 1970, no Bronx, nos Estados Unidos da América. Noutros trabalhos (Oliveira, 2018; Samico, 2013; Simões, 2019; Campos \& Simões, 2014), o hip-hop é evidenciado como um movimento que é composto por um conjunto de expressões artística variadas, que terminaram por se difundirem separadamente e em contextos e moldes deveras específicos, são elas: o breakdance, o $D j$, o graffiti e o rap. No caso do rap, este foi amplamente disseminado por todo o mundo, ao passo que ia adquirindo novas roupagens.

Como é sabido, entre os anos de 1970 e 1975, esses não-lugares (Augé, 1994), como o Bronx, eram dominados pela violência de gangues, pelo tráfico de drogas, pela prostituição e pela pobreza. Nesse interstício, precocemente o hip-hop se afigurou como um espaço onde os indivíduos podiam partilhar ideologias e vincular formas de consciência política, uma vez que as criações artísticas possuíam uma forte componente interventiva. Este caráter político é tão mais evidente, quando remetemos ao seu surgimento, isto é, às infames block parties, organizadas para promoverem a comunhão entre atores sociais e o espaço público (Forman \& Neal, 2004). Esta união que se dava

faixa intitulada Princess of the Posse. A música chamou a atenção da gravadora Tommy Boy Records, que assinou com Latifah.

${ }^{7}$ Dois grupos de rap feminino, emblemáticos na história do movimento hip-hop em Portugal. Para saber um pouco mais sobre a história dos grupos, bem como sobre a socio-história das artistas rappers mulheres em Portugal, consultar: https://www.muralsonoro.com/mural-sonoro-pt/2017/11/12/raprodues-dememria-1990-1997-percursos-da-invisibilidade 
no seio de um contexto urbano desfavorecido e marginalizado (Salvatierra, 2016), ainda hoje se encontra presente no movimento um pouco por todo o mundo. Aqui o espaço físico e os territórios são cada vez mais difíceis de delimitar, pois as fronteiras são frequentemente simbólicas, no sentido em que o espaço era retratado como um meio de reivindicação, de disputas, de afirmações identitárias e artísticas, mas era ainda tido como um símbolo de orgulho e de ostentação (Guerra \& Sitoe, 2019). Esta união, que teve o seu primórdio na década de 1970, é aquela que permitiu a solidificação de comunidades e de identidades coletivas, mas também a que veio evidenciar as desigualdades sociais (Remy \& Voyé, 1994).

Oliveira (2018) resgata nas suas pesquisas sobre hip-hop e mulheres o conceito de autorrepresentação para descrever um fenómeno que advém de uma construção social que se fundamenta em dinâmicas do it yourself (DIY) (Rose, 1994) e que se arrolam com o campo da produção artística (Bennett \& Guerra, 2018; Guerra \& Menezes, 2019). Partindo deste ponto, enfatizamos que a cultura hip-hop desde cedo que foi ao encontro de questões raciais, étnicas e classistas (Morad, 2018), com frequência associadas a contextos urbanos periféricos (Anderson, 2007), com a ideia de as discutir e questionar e, por conseguinte, estimular o empoderamento dos participantes nessa cultura. Então, o empoderamento reforça e incentiva as relações de proximidade criando um sentido de comunidade (Tarifa, 2012). As letras das canções e ainda as batidas e os ritmos, são, na verdade, um reflexo dos lugares em que os artistas vivem, bem como evidenciam os problemas e as vicissitudes que estes enfrentam diariamente, a um nível micro, tais como problemas familiares, a solidão e a pobreza, mas também num nível macro, associado às estruturas sociais e culturais (Weller, 2005) nas quais os artistas se circunscrevem e dentro das quais são construídas as suas criações artísticas. Sobre o conceito de autorrepresentação que é regatado por Oliveira (2018), torna-se importante enfatizar as dicotomias relacionadas com a presença dos homens no movimento hip-hop face à presença deficitária das mulheres (Mohammed-Baksh \& Callison, 2015). Vejamos, historicamente, os homens possuíram maior facilidade e liberdade dentro dos espaços públicos, e além disso foi-lhes conferida uma maior autonomia para se exporem publicamente. No caso da mulher e da sua participação no rap, a transposição da esfera privada para a esfera pública era desvalorizada. Porém quando o corpo era enfatizado e as atitudes sexuais (Tavares, 2010), estas eram alvo de uma profunda objetificação sexual. Tal divisão acontece em função da construção de imaginários espaciais (Forman, 2002) face à artista mulher no mundo do hip-hop, que 
dão origem e fomentam a discriminação e as desigualdades de gênero (Pough, 2004). Estas dicotomias, bem como os estudos sobre a representatividade feminina (Matsunaga, 2008; Tavares, 2012) na cultura hip-hop, evidenciam a permanência de conteúdos androcêntricos que enquadram a mulher como sendo subordinada.

\section{As mulheres no movimento hip-hop português}

Nas décadas de 1980 e 1990, a participação feminina nas diversas esferas da vida social ainda era escassa, fazendo com que se fosse óbvio aferir que a sua representatividade dentro do movimento hip-hop fosse residual. Devido a esta fraca notoriedade e participação por parte das mulheres, não é de abismar que as desigualdades de gênero ficassem fora dos tópicos mais badalados das canções que faziam sucesso na época. Pelo contrário, como os homens dominavam a cena, era reiterado que o sexo feminino surgisse categorizado como um objeto sexual (Tavares, 2010; Durham et al., 2013). Na verdade, concertámos que esta categorização e objetificação se têm intensificado ultimamente com a explosão de sub-gêneros como o trap-rap por todo o mundo, sendo de evidenciar artistas como o Offset ${ }^{8}$, nos Estados Unidos da América, o Matuê $\hat{e}^{9}$, no Brasil, e o $\$$ tag One $^{10}$ ou o $9 \mathrm{Miller}^{11}$ em Portugal. Apesar de serem de contextos geográficos completamente distintos e distantes, aquilo que os aproxima prende-se com a música, isto é, com o facto de estes se pautarem pela criação de canções, conteúdos performativos e textuais que prefiguram a mulher enquanto objeto sexualizado, como a "caça-fortunas" ou como leviana. As desigualdades de gênero, apesar de prematuramente terem estado presentes nas sociedades contemporâneas, acentuavam-se de forma acerada no movimento hip-hop (Pretorius, 2001; Aterianuis-Owanga, 2016). Historicamente, as mulheres no campo artístico eram descritas como as back vocals dos MC's, como flygirls ou como as groupies, e quando estas atuavam e adquiriam alguma forma de visibilidade mediática,

\footnotetext{
${ }^{8}$ Rapper Norte-Americano, membro do grupo Migos. Em 2019 lançou o seu primeiro álbum a solo, intitulado "Father of 4", em que a faixa "Clout", que conta com a parceria de Cardi B, foi a que a que obteve maior êxito.

9 É um rapper brasileiro que ficou conhecido com o seu single "anos Luz", lançado em 2017. É considerado um dos maiores nomes do trap-rap brasileiro.

${ }^{10}$ Rapper português, influente no universo underground e conhecido pela sua produção ao nível do traprap português.

${ }^{11}$ Miller estreou-se com um dos maiores rappers nacionais. Numa participação com Holly Hood, 9 Miller participou no tema Bazem daqui. Este tema está presente na mixtape de Xeg "Egotripping". 9 Miller fez parte da SuperBad e Show No Love. E "Filho da Guida" foi o seu primeiro grande sucesso. Mais informações em: https://www.mysound-mag.com/2017/12/10-cenas-sobre-vida-de-9-miller.html
} 
estas eram incentivadas a venderem uma imagem sensual e sexualizada (Guerra et al., 2017; Martins \& Guerra, 2019). Estas estavam à margem dos discursos e das performances e eram alvo de uma profunda estigmatização (Shelton, 1997).

Portugal, dentro desta hermética, assume-se como um caso paradigmático. Os movimentos hip-hop começam a ganhar força nos anos 1990, e como é óbvio, a participação feminina era parca, tal como acontecia noutros países anglo-americanos. Assim, tal como nesses contextos, também as canções de natureza sexual e de intuito estigmatizante emergiram na sociedade portuguesa, sendo de destacar artistas como Valete $^{12}$ ou o Mc Xeg ${ }^{13}$, que se encontravam um pouco na linha de Makkas ou de Bambino, uma espécie de old school do hip-hop. Porém, referimos que o contexto português era paradigmático por a maioria dos artistas que se estrearam e que deram ímpeto ao movimento em Portugal, com o lançamento de inúmeros sucessos, após o início dos anos 2000, pautavam-se pela produção de canções com um caráter interventivo e de denúncia, como uma forma de relato das vivências nas periferias urbanas do Porto e de Lisboa (Holston, 2009), como é o caso dos Dealema ${ }^{14}$ ou de Sam the $\mathrm{Kid}^{15}$.

Samico (2013) declara não ser possível apontar um marco que enuncie a participação feminina, uma vez que as mulheres sempre estiveram presentes, ainda que de modo passivo. No contexto português, apontasse para que a primeira rapper mulher que tenha emergido na indústria musical, isto é, a primeira a assinar um contrato por

\footnotetext{
12 Valete, nome artístico de Keidje Torres Lima, é um rapper português, de origem santomense. Começou a participar ativamente no movimento de hip-hop em Portugal no ano de 1997. É conhecido por pautas anticapitalistas e comunistas, e que retratam temas sociais da sociedade contemporânea. Atualmente, tem dois álbuns editados e cerca de 11000 cópias vendidas

${ }^{13}$ É uma das mais carismáticas figuras do Hip Hop nacional. Com uma carreira de mais de 15 anos, ao longo da qual editou os álbuns "Ritmo e Poesia" (2001), "Conhecimento" (2004) e "Outros tempos" (2009), para além das inúmeras participações que assinou em Mixtapes onde colaborou, XEG é, hoje, um dos mais respeitados e destacados membros da comunidade Hip Hop nacional, embora o seu reconhecimento não tenha, ainda, transcendido o circuito underground. Mais informações em: https://www.facebook.com/hhxeg/

${ }^{14}$ Dealema é um dos mais antigos grupos de hip hop português.Formado na década de 90, com membros de Vila Nova de Gaia e do Porto, nasceu da fusão do grupo Factor X (Mundo Segundo, Mike e DJ Guze) com os Fullashit (Fuse e Expeão), aos quais se juntaram Maze, e todos juntos formaram os Dealema que há 20 anos se mantêm no ativo exatamente com a mesma formação. São um grupo que se pauta pela transmissão de uma mensagem de denúncia dos malefícios da sociedade e do hip-hop

${ }^{15}$ É um rapper e produtor musical português. O lançamento do seu primeiro álbum, Entre(tanto), em 1999, foi influenciado pelos lançamentos de mixtapes por parte de DJ Bomberjack. Nesses anos muitos rappers queriam ser independentes de editoras, porém o segundo álbum de Sam The Kid, Sobre(tudo), acabou por ser editado pela Edel. Nessa altura o rapper já dava bastantes concertos, por exemplo no Hard Club, muitas vezes convidado pelo Mundo Segundo, nas sessões "Nova Gaia Sessions" que este último fazia.
} 
uma grande editora discográfica - a Universal - tenha sido Dama Bete ${ }^{16}$, em 2008. Dama Bete fez um descomedido sucesso com as músicas Definição do amor (2008) e Cala-te (2008). Esta segunda, talvez seja a mais emblemática, pelo facto de o videoclipe invocar padrões estético profundamente associados ao movimento hip-hop, como por exemplo o graffiti. Paralelamente, as suas roupas largas e a atitude irreverente contrariavam canções como a de Valete ou de Mc Xeg, bem como marcavam uma posição opositiva e encetavam à mudança, ao passo que se afirma como mulher e artista. Vejamos um excerto da letra de Cala-te (2008):

\begin{abstract}
"Questão: Porque há tanto MC parecido? / sem criatividade mais parecem um zumbido bzzz/ Já me cansa o ouvido se encontrar um mata-moscas / garanto estarão perdidos Pois o que fazem / melhor hip hop tuga e é assim só sabem falar nas costas/ fala a Frente mc fazes melhor / tou a cagar para o que dizes é só falar falar/ tou à espera que concretizes tens isto / e aquilo conheces este e o outro / aquele outro e o outro yah gravas num melhor estúdio / tens melhores beats parabéns sê feliz / mas chavalo não te estiques pois / dama bete isto dama bete aquilo / dama bete hii a pita não tem estilo/ Depois criticas e criticas e no final o quê?/ Dama bete participas no meu EP ?"
\end{abstract}

Dama Bete fez parte da banda sonora de um dos maiores sucessos televisivos juvenis, nomeadamente a série Morangos com Açucar, além de ter sido uma presença constante nos tops nacionais da MTV. Treze anos separam a data de lançamento desta música e a atualidade. De Igual para Igual (2008) foi o álbum de êxito de Dama Bete, um one hit wonder, e pouco depois do seu lançamento, a artista deixou de ser um nome recorrente no meio musical. Tropeçámos nesta música recentemente, ouvimo-la e pensámos que a situação portuguesa pouco ou nada mudou desde 2008, no sentido em que a luta que era levada a cabo por Dama Bete ainda se mantém essencial. Aliás, estas formas de protesto gentis e subtis (Corbett, 2018) utilizadas por Dama Bete, ainda se afirmam fundamentais. De facto, existem mais mulheres dentro do gênero em Portugal, contudo poucas são as que adquirem a visibilidade que a Dama Bete adquiriu na época. Assim, um pouco por toda a indústria musical portuguesa, existe um monopólio masculino (Tavares, 2012), e no caso do hip-hop esta presença é ainda mais acentuada, prevalecendo as ideologias de que falávamos inicialmente, associadas aos anos 80 e 90 (Tavares, 2010; Simões, 2019). Para o efeito, e com o objetivo de patentear os discursos das rappers mulheres que compõem o cenário da produção musical da atualidade,

\footnotetext{
${ }^{16}$ É uma rapper luso-moçambicana conhecida por ser a primeira MC feminina a solo a assinar com uma editora multinacional em Portugal.[1] O seu primeiro álbum, "De Igual para Igual (2008)", marcou a história do Hip Hop nacional, lançando a primeira carta para a afirmação da presença feminina no hip hop nacional.
} 
focámos a nossa análise em seis artistas que compõem a cena da cultura hip-hop atualmente. Umas mais comerciais do que outras. São elas a Cíntia, a Mynda'Guevara, a Nenny, a Chong Kwong, a Capicua, e a Lendária.

\section{Beat metodológico}

Existem algumas dimensões analíticas que, apesar de serem óbvias, são poucas vezes retratadas. Inúmeros artigos referem a diminuta presença das mulheres no movimento hip-hop (Hunter \& Soto, 2009; Hobson \& Bartlow, 2008; Harkness, 2011; Farrugia \& Hay, 2020), contudo, no campo académico português, ainda subsistem poucos estudos sobre as artistas que desse movimento fazem parte, ou seja, trabalhos que se debrucem sobre as lógicas de enfrentamento de várias materialidades estigmatizantes e sobre as formas de resistência (Mazer et al., 2018). As desigualdades de gênero, principalmente dentro da indústria musical portuguesa, são estruturais e ancoram-se em processos de socialização, sendo que também aqui o contexto urbano possui um forte impacto, pois estas desigualdades são por ele produzidas e reproduzidas, sendo um exemplo acabado disso o acesso condicionado a locais de concertos.

Deste modo, temos como princípio heurístico a demonstração dos trâmites em que as manifestações artísticas, produzidas e apresentadas por estas mulheres, podem e devem constituir matéria de intervenção social (Guerra, 2019), no sentido em que se assumem como atos de resistência (Farrugia \& Hay, 2020) e, além disso, denunciam e revelam problemáticas sociais diversas, tais como a questão da sexualização e objetificação da mulher (Tavares, 2012), o empoderamento, a estigmatização e a afirmação identitária. Estas artistas podem e devem ser tidas como agentes de mudança, uma vez que promovem a demarcação de espaços próprios que revelam e que retratam parte da sociedade que, caso contrário, seriam ignoradas ou desvalorizadas (Moura \& Cerdeira, 2021). Os conteúdos que as mesmas divulgam são insurgentes (Guerra, 2019) das realidades vividas e experienciadas, constituindo-se simultaneamente enquanto um elemento promotor de identidades coesas.

Neste sentido, a sociologia desempenha um papel fulcral. Enquanto ciência social o seu maior contributo reside na convenção e na apresentação de uma análise que permita a combinação entre indicadores que são objetivos e indicadores históricos e sociais, inerentes à ação social, aos seus símbolos e às representações que são feitas 
(Guerra, 2019). Partimos do pressuposto que as práticas artísticas podem beneficiar dos contributos sociológicos e, acima disso, que as análises sociológicas dos conteúdos e das realidades sociais, podem beneficiar largamente das práticas e das criações artísticas, no sentido em que estas prefiguram e retratam discursos sobre as sociedades (Silva et al., 2018; Guerra, 2019). Então, com a elaboração deste artigo, pretendemos observar de que modo é que as músicas e os videoclipes destas artistas refletem os problemas sociais, especialmente aqueles que se relacionam intimamente com as dificuldades sentidas no âmbito da inserção e da sua valorização, enquanto artistas, dentro do movimento hip-hop em Portugal.

Propomos - a partir de uma metodologia qualitativa - apresentar uma análise de conteúdo de uma canção para cada uma das seis artistas previamente enunciadas, bem como é nosso interesse focarmo-nos nas estéticas a essas canções associadas, retratadas nos videoclipes de cada canção. Em suma, pretendemos realçar - numa lógica epistemológica - o domínio da arte enquanto reflexo das realidades sociais, oferecendo novas interpretações sobre o campo das artes, aqui neste caso, sobre a música rap em concreto. Para a seleção de cada artista tivemos em consideração alguns aspetos. Primeiramente, procuramos selecionar canções recentes, mas também tentámos que o conteúdo e/ou o videoclipe transmitissem a imagética da resistência e da afirmação, para estabelecermos uma ponte com Dama Bete. Como propomos uma análise descritiva dos conteúdos (Guerra, 2019), provimos à criação de um conjunto de temáticas analíticas que foram elaboradas posteriormente, sendo elas: i) a sexualidade; ii) o empoderamento; iii) a resistência; iv) o feminismo; v) a afirmação.

\section{Hip-hop, simbologia e mensagens emergentes}

As pesquisas sobre o rap, de um modo geral, têm-se focado em duas áreas. A primeira diz respeito a um retrato das mulheres nos conteúdos artísticos que são produzidos, como por exemplo nas letras das canções ou nos videoclipes (Becker, 2007; Berry, 2003; Hunter, 2011). A segunda área refere-se às relações entre as mulheres, o rap, marketing e os média, estando aqui inerente o campo das representações (Peddie, 2006).

No que toca à primeira área, o conceito de hegemonia masculina nas investigações daí recorrentes é pedra de toque (Mohammed-baksh \& Callison, 2015), no sentido em que o mesmo é associado é associado a processos de liderança e ao domínio 
do homem sobre a mulher. No caso do rap, a dominação e a hegemonia masculina são visíveis no número de canções que eram produzidas e lançadas, focadas num retrato sexualizado e objetificado da mulher e, claro está, apoiadas pelo sucesso e destaque que estas obtinham na indústria musical (Hobson \& Bartlow, 2008). Assim, o rap, apesar de ser pautado por estas lógicas de dominação hegemónica masculina, também tem vindo a absorver outras ideologias que, surpreendentemente, o tornaram ainda mais fechado, exclusivo e segregador, algo que advém dos próprios processos de reconfiguração da indústria musical.

Atualmente, uma vasta maioria de artistas dentro do gênero do rap ainda se regem por estes estereótipos profundamente segregadores do gênero feminino. É aqui que enquadramos o nosso artigo, uma vez que consideramos as produções das artistas previamente referenciadas como formas de protesto subtil e gentil (Corbett, 2018). No nosso entender, as canções que foram alvo de análise assumem-se como um manifesto de um ativismo silencioso e latente, através do qual são utilizadas dinâmicas de fazer com o intuito de promover o envolvimento, bem como de influenciar e efetuar mudanças (Malcomson, 2019). Tal como Corbett (2018) menciona, deve ser feita uma visualização do mundo em que queremos viver, e acima disso devem ser identificadas as oportunidades para o concretizar.

Neste contexto, consideramos que as canções analisadas são uma ferramenta para tal, mas não o objetivo final. São antes um meio de promoção do pensamento e da reflexão crítica, mas também emergem como um modo de luta, de denúncia e de empoderamento das próprias artistas, isto é, como estratégias conscientes que fomentam a afirmação identitária e o empoderamento. A emergência de rappers mulheres num mundo global vem questionar a subjetividade e os estereótipos associados à matriz da mulher artista branca, eurocêntrica, heterossexual e burguesa (Salvatierra, 2016). Além disso, vem colocar em causa algumas dicotomias entre o Norte e o Sul Globais, especialmente pelo facto de no Sul Global as mulheres possuírem maior força nesta luta e neste processo de afirmação face ao Norte, especialmente quando pensamos em Portugal.

Posto isto, a primeira artista que iremos analisar é Cíntia. Esta jovem artista de vinte anos é natural da Apelação (Loures), e lançou a sua primeira música há dois anos. A música que pretendemos analisar intitula-se Grana (2019) e foi escrita pela artista a pensar na sua namorada. Partindo deste ponto, estabelecemos um paralelismo com os nossos contributos iniciais, quando referíamos que as músicas tendencialmente retratam 
as mulheres como um objeto sexual, mas também como as "namoradas" ou as "mães dos filhos" (Tavares, 2012), no rap masculino. Apesar de serem poucas, as músicas que Cíntia já lançou nas plataformas como o YouTube ou Spotify, assumem-se como comerciais e, além disso, retratam temas que são frequentemente abordados por homens, tais como as relações amorosas, o interesse na mulher pelo prazer ou a traição. Vejamos abaixo alguns frames do videoclipe:

Figura 1 - Frames do videoclipe de Grana, de Cíntia

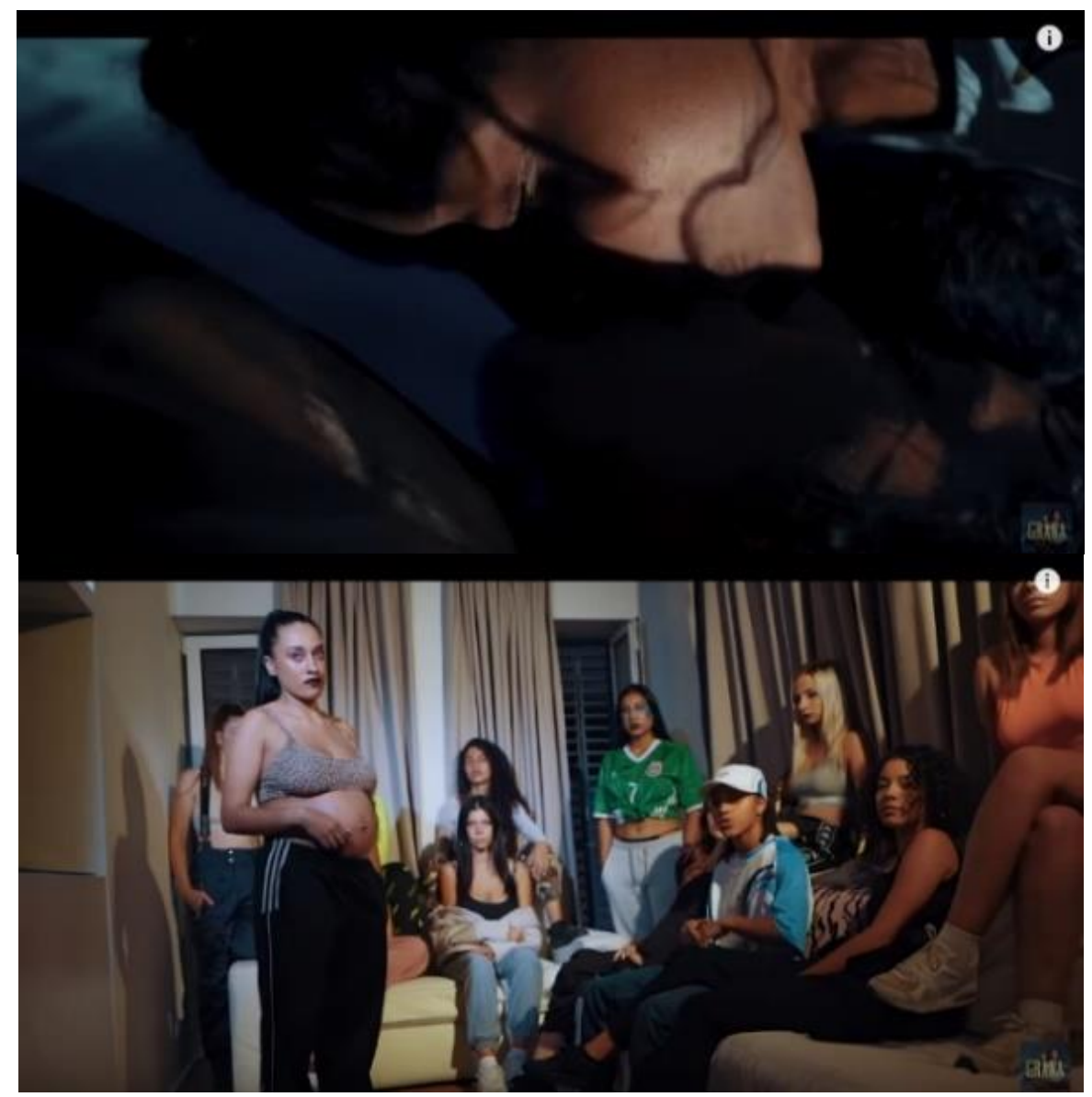

Fonte: Cíntia, “Grana”, Loko Night, 2019

Seguindo a linha de pensamento anterior, considerámos que Cíntia vem enfatizar algumas temáticas relevantes. Como já referimos, aos homens foi-lhes concebida histórica e socialmente a facilidade de exporem publicamente aspetos da sua vida privada (Oliveira, 2018), sendo esta ideia quebrada pela artista, visto que a canção Grana se refere à sua vida privada, isto é, à sua sexualidade e, além disso, também temos presentes questões relacionadas com a sexualidade (O’Toole, 2000), aspeto esse que nos possibilita evidenciar a questão da discriminação positiva. Se este videoclipe 
tivesse sido produzido por um artista do sexo masculino, no qual era retratada uma relação homossexual, muito provavelmente não teria o mesmo tipo de atenção que o de Cíntia teve, pois ainda se perpetua a ideia do homem heterossexual e gangster dentro da cultura hip-hop em Portugal ${ }^{17}$, enquanto no caso da mulher identificamos o incentivo à expressão da sua sexualidade (Oware, 2011). Ainda quanto ao videoclipe, destacamos que apenas figuram mulheres, uma delas grávida, revelando também uma certa contestação aos padrões estéticos impostos pela sociedade, enaltecendo por oposição a mulher nas suas diversas formas. Atentemos a um excerto da sua música,

Mãos no teu pescoço para te deixar doida/ Sussurros no teu ouvido te meto à toa/ Logo tu que adoras ver a lua/ E eu que adoro te ver nual No meu room a mexer a bunda/ Assim tá bom miúda não muda (Cíntia, Grana, Loko Night, 2019)

Estudos sobre esta questão são praticamente inexistentes. Mohammed-baksh e Callison (2015) enunciam a existência de artistas que acabam por adotar os discursos que são provenientes de um conjunto de indivíduos e de meios que promovem a masculinidade hegemónica, contudo essas explicações não são suficientes para percebermos conteúdos artísticos como este de Cíntia. Deste modo, iniciamos a nossa incursão analítica, mantendo em mente que tal como Becker (2007), é premente que se encare a arte como uma forma de dizer sobre a sociedade, visto que se torna possível relacionar estas tipologias de discursos, tais como a sexualidade ou as relações amorosas homossexuais, por exemplo, com modos de afirmação por parte da artista. Dado que esta apenas possui vinte anos, podemos ainda questionar até que ponto este conteúdo - bem como outros, dentro das temáticas que enunciamos previamente demonstram um ethos que caracteriza a juventude portuguesa, no sentido em que este tipo de conteúdo é tido como sendo apelativo e dado que conta com um elevado número de visualizações em plataformas como o YouTube ${ }^{18}$. Enquanto forma de dizer, esta criação artística ilustra possíveis representações dos jovens face à sexualidade, à homossexualidade - que até há bem pouco tempo em Portugal era tabu - mas também sobre as relações amorosas e outras componentes estéticas e discursivas.

\footnotetext{
${ }^{17}$ Esta categorização advém especialmente do facto de o hip-hop ser um género musical que advém do bairro social, locais segregados, marginalizados e excluídos onde - no âmbito do senso comum - impera a criminalidade e a violência (Sousa, 2018; Guerra, 2002)

${ }^{18}$ Quase dois milhões de visualizações.
} 
A música popular e mais concretamente o hip-hop, são uma importante fonte de modelos de valores culturais que se relacionam com a construção de identidades de gênero (Frith \& McRobbie, 2005; Nieto-Álvaro, 2012; Herd, 2015). As produções femininas no hip-hop são um campo de investigação que se encontra em modo crescente (Berggren, 2014), dado que podem ser entendidas como um veículo cultural e geracional relevante, que permite o empoderamento das mulheres e que encoraja modos críticos feministas de se estabelecer uma análise crítica (Richardson, 2013). Pough (2007) argumenta que estas literacias feministas promovem análise situadas que expõem o sexismo, a misoginia, poder, desigualdades e exploração (Richardson, 2013). Do ponto de vista feminista, alguns autores afirmam que a música popular, sendo um tipo de produto que é produzido numa sociedade machista, promove e sustenta as desigualdades de gênero, daí que se torne essencial a existência de produtos artísticos e culturais que contrariem este modelo. Mais, a maioria das pesquisas que foram feitas sobre música e sobre as identidades, desconsideraram as experiências femininas, ou então as mesmas foram reduzidas e classificadas como insignificantes (Kearney, 2007; McRobbie \& Garber, 1975). Apenas uma visão feminista dos estudos subculturais demonstrou que as mulheres deveriam ser percecionadas enquanto atrizes principais no seio da maioria dos grupos juvenis que eram tradicionalmente estudados, por exemplo. Então, o campo da produção artística da cultura hip-hop, em alguns contextos, tem avançado rapidamente, no sentido da sua estruturação - vejamos o caso do Brasil como um exemplo, com a emergência de um número crescente de grupos femininos. As mulheres têm procurado historicamente afirmarem-se enquanto sujeito social, enquanto reivindicam diversas frentes de opressão. Trata-se da necessidade da afirmação da identidade feminina que é socialmente produzida e construída (Tavares, 2012). Deste modo, as restantes temáticas que foram criadas para a elaboração deste artigo encontram-se interrelacionadas. Visto que os discursos são flexíveis, os mesmos poderiam ser classificados em diversas temáticas simultaneamente, contudo - para o efeito do artigo - procuraremos apresentar a informação de forma sistemática.

Quanto à temática do empoderamento, começamos desde logo por associar a mesma aos contributos de Hall (1997), no sentido da rutura de regimes. Os conteúdos destas artistas foram perspetivados como uma forma de promoção da independência e da autoafirmação. Estas artistas portuguesas apresentam-se como um meio e como agentes sociais capazes de desafiarem o patriarcado, além da necessidade de demonstrarem que as suas produções são dignas de reconhecimento. Dentro das 
temáticas do empoderamento e da afirmação, destacamos a Mynda'Guevara ${ }^{19}$, a Nenny ${ }^{20}$ e a Chong Kwong ${ }^{21}$.

Primeiramente, Mynda 'Guevara é uma rapper de vinte e três anos, filha de caboverdianos e que nasceu e foi criada no Bairro da Cova da Moura ${ }^{22}$, localizado na Amadora, em Lisboa. A artista canta e escreve sobre o que significa ser uma mulher negra no mundo do rap, um meio artístico dominado por homens. Também o seu nome artístico é sinónimo de revolução e de resistência, visto que ela se inspirou em Che Guevara. O seu é também deveras interessante, visto que Mynda é formada em Marketing e Comunicação, e iniciou-se no mundo da música a cantar refrões de outros artistas. Novamente, vemos espelhado o papel histórico e social que era e é conferido às mulheres na indústria musical (Oliveira, 2018; Tavares, 2012; Samico, 2013). A música que nos propomos analisar - Na Nossa Língua ${ }^{23}$ (2020) - foi a primeira que a artista lançou em que o idioma cantado não é o crioulo.

$\mathrm{Na}$ letra, a artista começa de forma imediata a fazer referência a outras mulheres, transmitindo a ideia de que também não é valorizada por outras mulheres/artistas, especialmente no que toca ao seu percurso de vida, vejamos: Ela diz que é a boss, não sabe o que é vir do ghetto hustle como nós (Mynda'Guevara, Na Nossa Língua, Independente, 2020). Paralelamente, Mynda ainda faz referência ao facto de não lhe ser dado mérito, sendo que com frequência - como já referimos - as músicas que são interpretadas por mulheres, especialmente na cultura hip-hop são desvalorizadas, fazendo alusão ao facto destas terem sido produzidas por homens, não sendo conteúdos originais: Sempre a mesma história a mesma lengalenga/ Sou eu quem escreve as minhas barras/ Futura lenda (Mynda'Guevara, Na Nossa Língua, Independente, 2020).

Quanto à representatividade da mulher na cultura hip-hop, voltamos a identificar referências que se prendem com a dualidade entre o espaço privado e o espaço público porém numa lógica diferente de Cíntia -, no sentido em que aferimos os sentimentos e as dicotomias entre homens e mulheres, verificando a necessidade de a artista

\footnotetext{
19 Consultar este link: https://www.dn.pt/cultura/mynda-guevara-o-rap-tambem-e-para-mulheres10647899.html

${ }^{20}$ Consultar este link: https://observador.pt/2020/02/27/nem-billie-eilish-portuguesa-nem-lauryn-hill-devialonga-nenny-e-nenny-e-chegou-para-mandar/

${ }^{21}$ Consultar este link: https://blitz.pt/principal/update/2019-08-31-Quem-e-Chong-Kwong--A-historia-darapper-com-muitas-misturas-que-e-a-nova-sensacao-do-hip-hop-em-Portugal

22 Considerado um dos bairros sociais mais perigosos do país. Disponível em: https://rr.sapo.pt/2016/11/07/pais/cova-da-moura-o-bairro-do-muro-invisivel-em-que-os-tijolos-somosnos-e-eles/noticia/67716/

${ }^{23}$ Disponível em: https://www.youtube.com/watch?v=pWCZz1qJZ6o
} 
demonstrar as suas lutas: Somei lágrimas, naveguei sem medo/ Agora olha para mim, vê que sou capaz (Mynda'Guevara, Na Nossa Língua, Independente, 2020). Através deste excerto, conseguimos patentear aquilo que Forman (2002) afirma face à criação de imaginários para a artista mulher, isto é, os imaginários que referimos no início deste artigo, relacionados com a discriminação e com a problemática em torno do gênero, vemos - exemplificados através de excertos como estes - que estas mesmas construções também fazem parte dos imaginários das mulheres artistas. À semelhança de Cíntia, no videoclipe só surgem mulheres e além disso, como pano de fundo temos uma ode a outras artistas mulheres - tais como a Queen Latifah ou a Missy Elliot- que revolucionaram a cultura rap, demonstrando que as mulheres podem ir mais além, e contrariando os discursos misóginos e a normatividade masculina (Mohammed-baksh \& Callison, 2015), tenhamos atenção aos seguintes frames do videoclipe em questão:

Figura 2 - Frames do videoclipe de Na Nossa Língua, de Mynda’Guevara

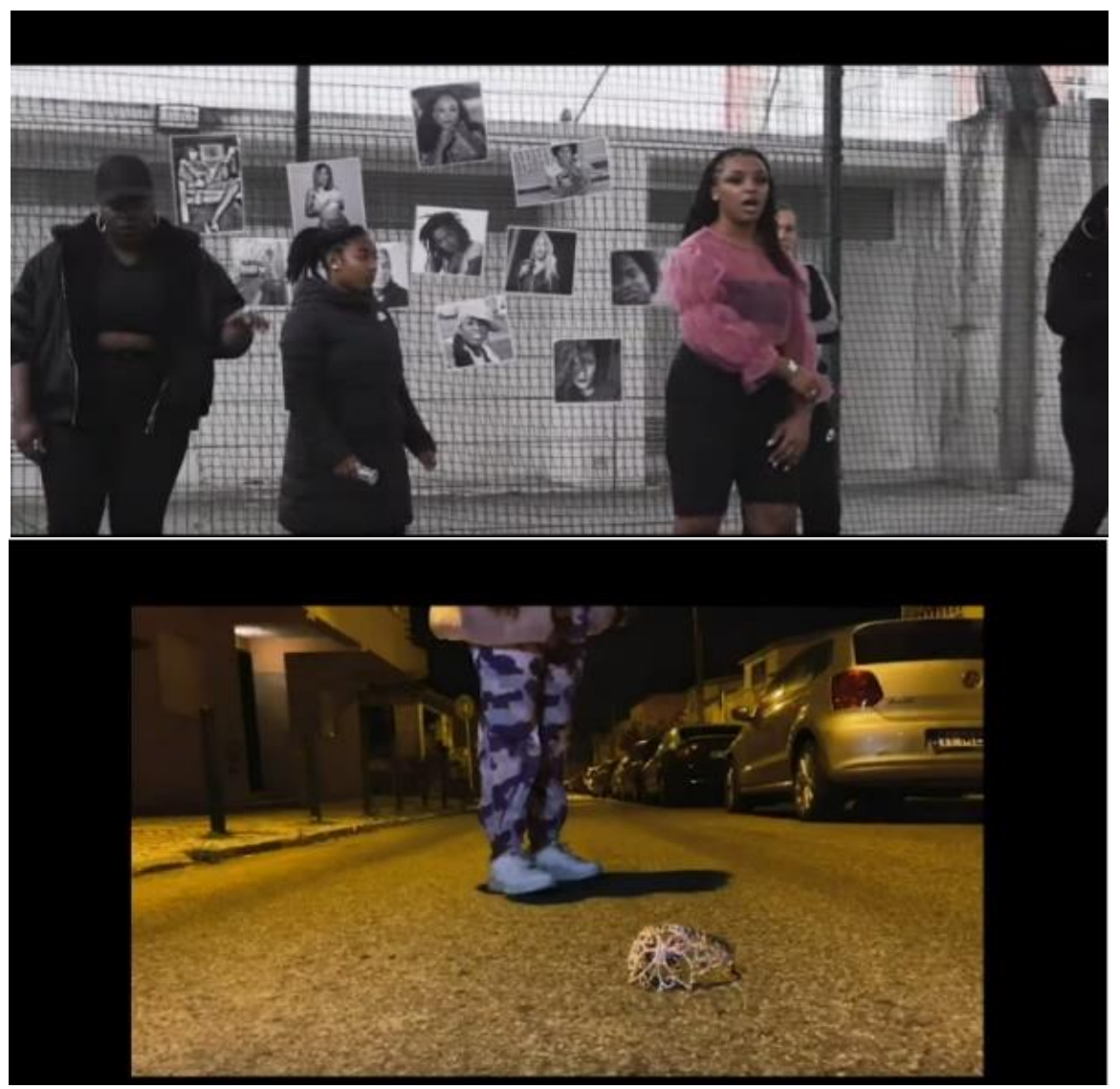

Fonte: Mynda'Guevara, “Na Nossa Língua”, Independente, 2020.

Essas produções artísticas acabam por constituir um estilo musical, uma espécie de subgrupo que se centra no conteúdo dos discursos que são expressos nas letras 
(Tavares, 2012; Simões, 2019), conferindo-se como uma oportunidade de difusão de propostas que extrapolam as representações artísticas. O próprio tom que é utilizado da denúncia, da violência ou da afirmação - enfatizam estas dinâmicas, como por exemplo, Não vale a pena virem copiar vocês não passavam no testel A preta que veio do ghetto do nada, quer estar na boca do povo (Mynda'Guevara, Na Nossa Língua, Independente, 2020).

Esse último excerto apresentado foi categorizado como sendo referente à temática da afirmação. Tal categorização prendeu-se com três motivos: o tom que é utilizado quando refere questões raciais - que veio do ghetto, do nada - depois também pela necessidade de se afirmar enquanto artista dizendo que quer andar na boca do povo, isto é, quer ser conhecida, quer que lhe seja conferido o sucesso que ela acha que merece e, por último, consideramos ser uma forma de afirmação quando a mesma refere que os restantes não passavam no teste, fazendo alusão à ideia de que ninguém é melhor do que ela.

A mesma tipologia de análise se segue para a temática do empoderamento, quando a mesma refere: Agora olha para mim, vê que sou capaz. Esta frase deixa de ser cantada e passa a ser falada sendo a última parte proferida com uma acentuação de afirmação enquanto, no videoclipe, é feito um close up da sua cara (posição de enfrentamento e de afirmação). Por fim, nos últimos frames do vídeo ${ }^{24}$ mostra Mynda a pisar uma coroa, passando claramente a mensagem de oposição aos estereótipos subjacentes à presença das mulheres no rap. Neste último frame considerámos o ato como uma forma de protesto gentil (Corbett, 2018).

Pegando nesta última ideia da simbologia de pequenos gestos e objetos nos contextos dos videoclipes, avançamos com a nossa análise para a artista Chong Kwong. Chong Kwong é o nome artístico de Vanessa Pires, nascida na Cova da Moura - tal como Mynda'Guevara - mas que viveu entre a Damaia, o Cacém e o Barreiro, em Lisboa. Possui descendência africana, portuguesa e asiática e durante sete anos deixou a música em pausa. Aproveitou esse tempo para viver em Macau e exerceu atividade profissional a trabalhar no turismo e na organização de eventos. O seu nome artístico é uma homenagem ao seu bisavô, daí que possamos aferir que as suas músicas possuem sempre um registo biográfico, particularmente relacionado com a sua família e com

\footnotetext{
${ }^{24}$ A fotografia em baixo na figura 2 , acima representada.
} 
relações amorosas, mantendo sempre uma mensagem de empoderamento e feminista (Richardson, 2013).

A música que selecionamos intitulada Chong Kwong $^{25}$ foi a primeira que a artista lançou após o seu regresso à indústria, sendo que se caracteriza por ser um registo biográfico. Nesta canção de Chong Kwong também conseguimos desde logo identificar, tal como nos menciona Becker (2007) formas e modos de dizer sobre a sociedade e, neste caso concreto, sobre a indústria musical e sobre o hip-hop. Por um lado, a temática da resistência, que mais uma vez vem contestar a objetificação sexual da mulher, quando a mesma refere:

Não meto nudes em clipes, no thank you/ Não vendo o corpo por beats, boy fuck you, ou ainda, Nessa, sou teu ghost writer/ Entra no meu videoclipe, Baby, não sou dick rider (Chong Kwong, Chong Kwong, Independente, 2019).

Neste último excerto, a questão do ghost writer é algo paradigmático e característico da indústria musical, indo ao encontro do que já foi abordado sobre o facto de as produções artísticas das mulheres não serem valorizadas, visto que nos Estados Unidos esta pratica é muito comum (Balestrini, 2019). São outras pessoas homens normalmente - que escrevem os conteúdos das músicas para artistas femininas. Ainda nestes excertos temos patente a problemática da sexualização, uma vez mais. Tal como nas músicas anteriores, no videoclipe o destaque são as mulheres.

Figura 3 - Frames do videoclipe Chong Kwong, de Chong Kwong

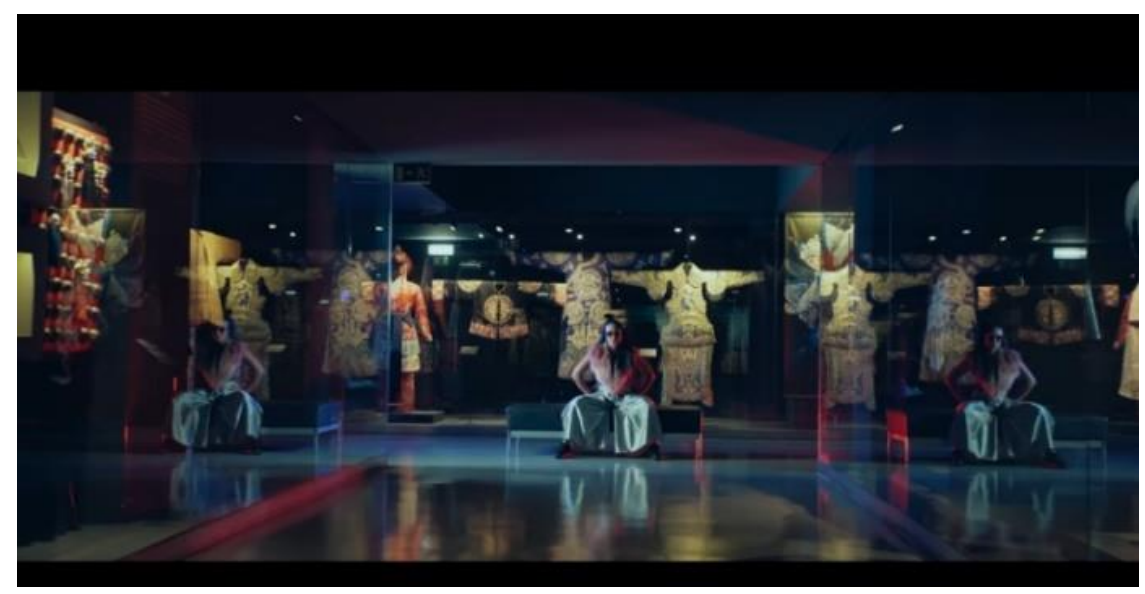

${ }^{25}$ Disponível em: https://www.youtube.com/watch?v=ZYohSB2c3i0 


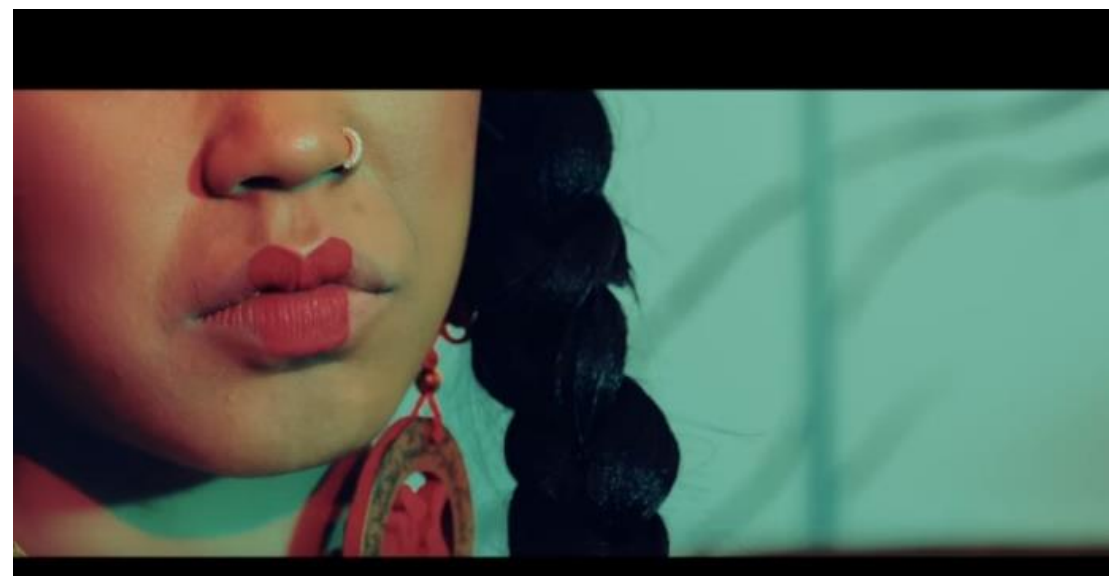

Fonte: Chong Kwong, Independente.

Nestes dois frames retirados do videoclipe da artista destacamos dois elementos essenciais que, na verdade se relacionam com os conteúdos das letras. Por um lado, ambos fazem referência à sua multiculturalidade, isto é, à sua identidade. Esta problemática da identidade também transparece nos discursos, especialmente quando a mesma canta, Tenho barras à Pequim, eu sou made in China (...) Primeira rapper gangsta anime, Yakuza (Chong Kwong, Chong Kwong, Independente, 2019). Para este pequeno excerto da letra identificamos duas temáticas, para a primeira parte da frase vemos espelhada uma forma de afirmação identitária e artística, no sentido em que reconhece a sua multiculturalidade e expõe-na, mas também na segunda parte da frase evidenciamos a temática do empoderamento (Orange, 1996). Ela é a primeira rapper que produz conteúdo deste gênero, com elementos da cultura asiática. Ainda para a questão da afirmação pessoal, tal como acontecia com Mynda'Guevara, Chong Kwong menciona na música a sua afirmação artística face aos homens, numa lógica de exigência de reconhecimento: Please, bitch sit down e decora o meu nome, boy (Chong Kwong, Chong Kwong, Independente, 2019).

Se olharmos de forma atenta para a primeira imagem que é apresentada (ver Figura 3), verificamos que o videoclipe foi gravado num museu. Contudo, aquilo que queremos realmente destacar é que as imagens de fundo são referentes a trajes que eram utilizados por homens, de origem asiática, e - como uma mensagem/protesto subliminar (Corbett, 2018) - a artista surge no centro enquanto elemento de destaque. Estamos então diante de uma forma clara de afirmação e de empoderamento, que pode ser complementada com os seus discursos, tais como: No meu rap Kingdom, e também Da Tuga a Hong Kong/ Eu matei o King Kong/Mothafucka, o meu nome é long/ The Queen 
Chong Kwong, ei/ Eu sou a Queen Kwong, ei (Chong Kwong, Chong Kwong, Independente, 2019).

Avançando na nossa análise, Nenny também se afigura neste contexto como um elemento de elevada importância, visto que se tem assumido como uma das rappers revelação do ano, tendo obtido um sucesso enorme com a sua música $\operatorname{Sushi}^{26}$ (2019). A rapper de dezanove anos viu a sua música divulgada pela rádio de forma massiva e assumiu-se como um fenómeno repentino, contudo, inúmeros indivíduos - em plataformas como o YouTube por exemplo - desvalorizam as suas produções, principalmente por a mesma contar com o apoio do grupo Wet Bed Gang ${ }^{27}$. Esta música foi selecionada, em grande parte, devido ao sucesso que ela fez, sendo que conta com cerca de doze milhões de visualizações no YouTube, aspeto que se destaca largamente em comparação às outras artistas que temos vindo a analisar. O caso de Nenny tornouse alvo de interesse precisamente pelo êxito repentino que ela teve. As suas músicas tendem a focarem-se na afirmação identitária pessoal e artística, ou seja, enquanto mulher e mulher negra. Nesse contexto, tornou-se pertinente compreender de que modo é que estas temáticas surgem nas suas produções, quando a mesma conta com o apoio de uma banda que produz letras e videoclipes que promovem a heteronormatividade masculina.

Figura 4 - Frames do videoclipe Sushi, de Nenny

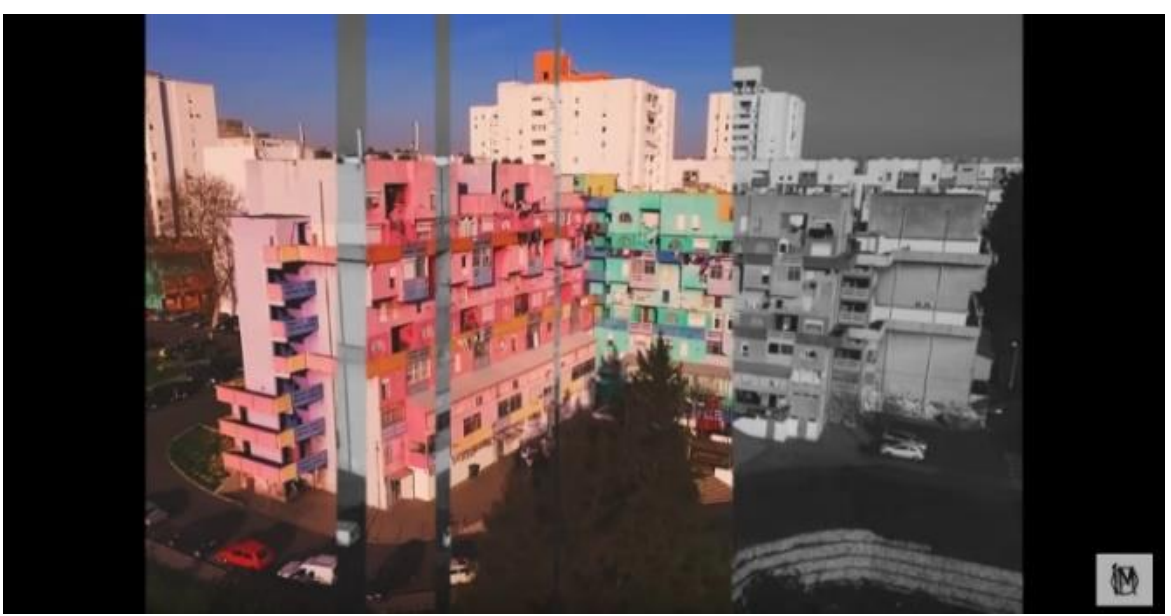

\footnotetext{
${ }^{26}$ Disponível em: https://www.youtube.com/watch?v=j-3LjMES1sl

27 Um grupo português de rap de Vialonga. Os mesmos receberam reconhecimento nacional com a música não tens visto. Atualmente contam com milhões de visualizações no YouTube e no Spotify. As suas produções musicais possuem o cunho a Sony Music e da WBG Records.
} 


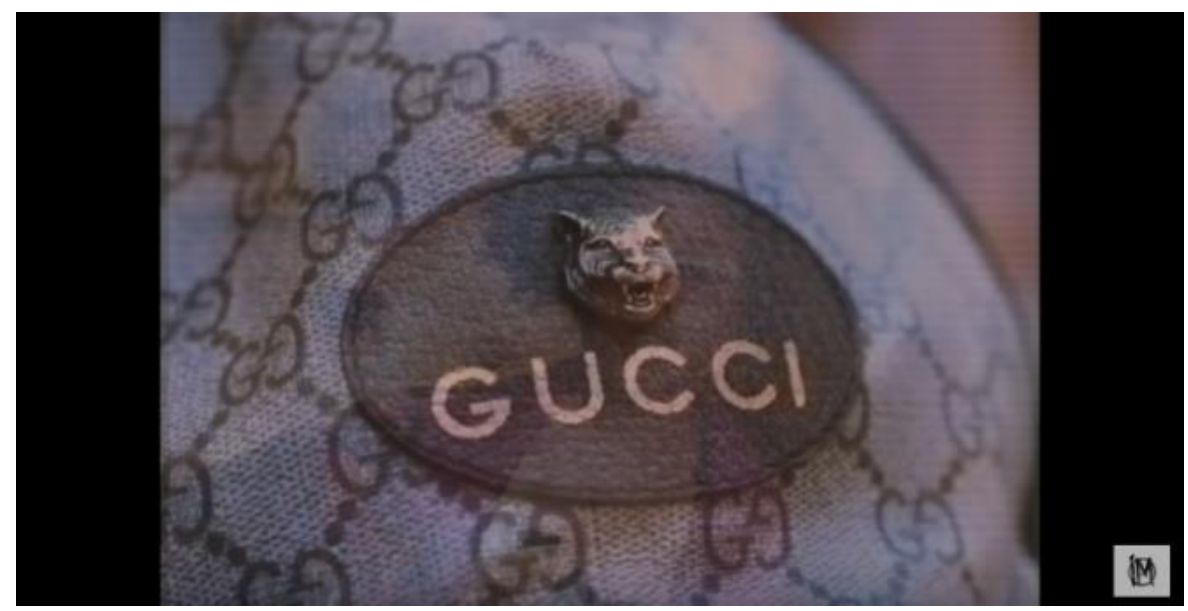

Fonte: Nenny, “Sushi”, I.M, 2019.

Desde logo, nas duas imagens acima apresentadas, identificamos elementos identitários. A problemática do bairro e do território e a questão da moda (Guerra \& Figueiredo, 2019), enquanto símbolo de ostentação e de afirmação perante outros (White, 2013), algo muito presente em artistas como Sam the Kid, o Piruka ${ }^{28}$, o Dillaz ${ }^{29}$, e até mesmo em artistas como a Mynda'Guevara. Trata-se de dualidades que demonstram o percurso da artista, bem como resumem a sua afirmação no campo musical português, pois Nenny canta que Eu andava com marcas de lama/ Hoje se eu ando com marcas é Gucci, mas também Eu sou a campa p'ra tua fama/ Nigga quer vir contra mim/ Rihanna Man Down Like Ram pa pam pam pam (Nenny, sushi, 2019, I.M).

Essa temática da afirmação é ainda mais enfatizada na sua música, por oposição e comparação às restantes músicas que analisamos. Tal comportamento, no nosso entender, deve-se ao facto de esta ter feito sucesso de forma repentina, ou seja, a mesma sente necessidade de se afirmar perante os outros artistas, assumindo uma postura um tanto quanto agressiva e defensiva, que revela, por um lado, a conquista alcançada, mas também, o receio e as incertezas face à durabilidade do seu sucesso, visto que a sua música mais recente não possuiu o mesmo impacto que Sushi.

\footnotetext{
${ }^{28}$ É um rapper português. Os seus maiores êxitos são "Se Eu Não Acordar Amanhã", "Salto Alto", "Não Se Passa Nada", "Vim para ficar", "Só Vim Dizer Yau", "Não Faz Isso", "Louco" e "Chora Agora". Em 1999 e 2000, sem qualquer apoio de uma grande editora (recusou várias ofertas de contratos com grandes gravadoras), obteve centenas de milhares de seguidores no YouTube.

29 Artista de hip hop e rap conhecido por músicas como "Mo Boy", "1100 Cegonhas" e "Não Sejas Agressiva". Os clipes dele já foram vistos mais de 147 milhões de vezes no YouTube.
} 
Além disso, Nenny enquanto artista, continua a promover discursos que, no nosso entender, podem ser categorizados como sendo referentes à temática da resistência, tais como Aqui ninguém tem culpa se o teu boy canta shit/ Eu ganho tudo memo que alguém boicote the shit (Nenny, Sushi, I.M, 2019).

Este último excerto é interessante do ponto de vista analítico, não só por ser representativo da temática em causa, mas também pela forma como ele é dito, isto é, a artista faz referência ao teu boy, acabando por estar implícita uma figura feminina, tal como nos discursos de Mynda. Avança ainda cantando: aqui é matéria futurista no meu guimbo/ O teu nigga aqui só foi turista tipo gringo (Nenny, Sushi, I.M, 2019).

Por fim, o empoderamento encontra-se presente de forma latente, no sentido em que também encontramos semelhanças com o discurso de Chong Kwong. Vejamos que Chong Kwong canta: The Queen Chong Kwong, ei/ Eu sou a Queen Kwong, ei (Chong Kwong, Chong Kwong, Independente, 2019), em referência ao mundo do hip-hop. Paralelamente, Nenny canta: Que sa'foda o king/ Essa jungle é da queen Kong (Nenny, sushi, I.M, 2019).

Posto isto, restam-nos duas artistas: Lendária e Capicua. Apesar de também encontrarmos nos seus conteúdos as temáticas do empoderamento e da afirmação, estas salientam outros tópicos que são interessantes e ilustrativos da sociedade portuguesa, principalmente no que diz respeito às representações que são feitas sobre as mulheres. Assim, consideramos que estas duas artistas se focam de forma substancial na temática da resistência e do feminismo. Comecemos por Lendária.

Figura 5 - Frames do videoclipe Diz-me Lá, de Lendária

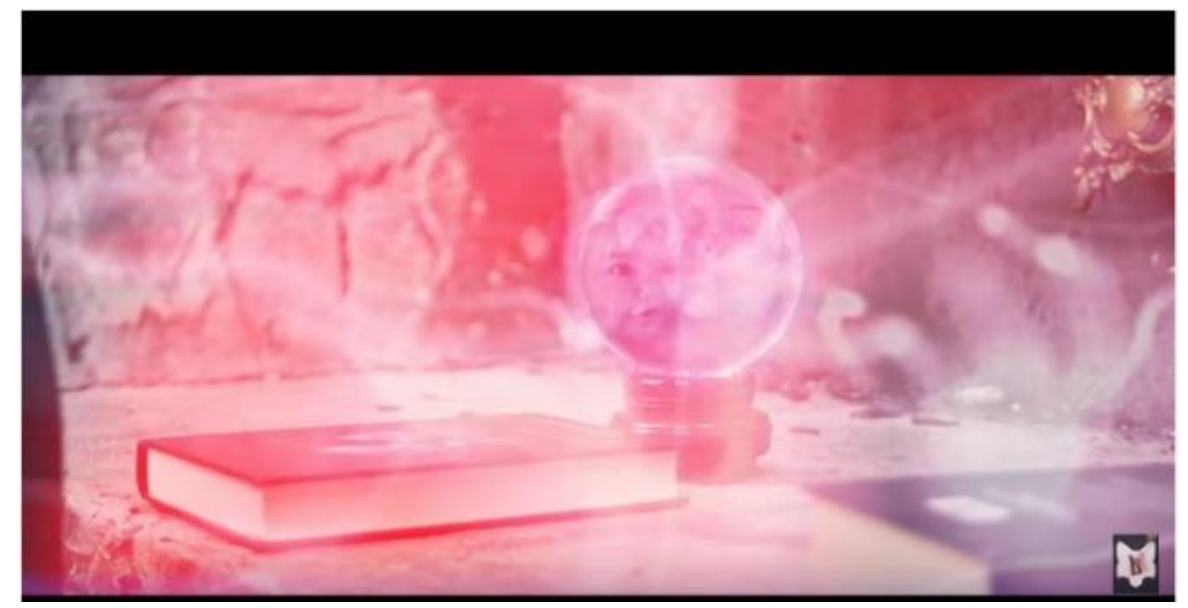




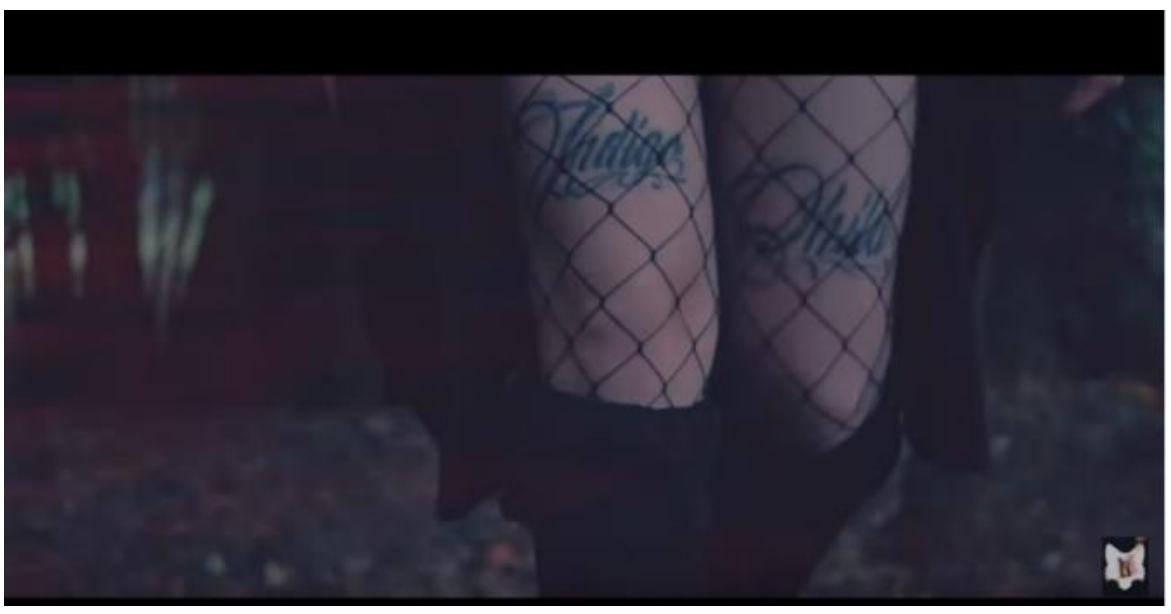

Fonte: Lendária, “Diz-me Lá”, Independente, 2019

Lendária é natural de Vila Nova de Gaia e a música que foi selecionada é a Diz-me $L a^{30}$, um single da mixtape Mandrágora. Esta artista, nas suas canções, sempre abordou a temática do empoderamento, porém, nestes últimos trabalhos artísticos, surgem amiúde temas relacionados com a maternidade - como podemos ver a referência ao seu filho nos frames do videoclipe (ver Figura 5). Ligadas à abordagem da maternidade, emergem temáticas como o feminismo e a resistência (Skeggs, 2012). Vejamos alguns exemplos de conteúdo que fazem referência a esta questão da resistência: Não me arquétipo em função da vossa língua/ Olha bem que 'tá aqui/ Queriam que me calasse sem escrever nem uma linha, e também, Eu sei que a minha vida provoca um certo interessel E que o vosso desejo era mesmo que desaparecesse (Lendária, Diz-me Lá, Independente, 2019). A temática da maternidade é de extrema relevância, visto que as mulheres, especialmente as que se encontram no mundo da música, são frequentemente obrigadas a escolher entre as suas famílias e as suas carreiras, por oposição aos homens. Novamente, assistimos à perpetuação da imagem da mulher cuidadora (Chaney \& Brown, 2015) que é perpetuada através de um imaginário comum que se instituiu de modo alargado. A maternidade é vista com regularidade como o fim da carreira das mulheres, enquanto a paternidade é encarada como sendo apenas mais uma fase na carreira musical dos homens, podendo até - para alguns - ser um ponto de viragem nos seus estilos e gêneros musicais produzidos, como aconteceu com o Piruka.

\footnotetext{
${ }^{30}$ Disponível em: https://www.youtube.com/watch?v=EOvZgEZzE3w
} 
Além da centralidade da resistência, Lendária nos seus discursos ainda faz referência à sua vida pessoal (Oliveira, 2018), tal como Cíntia e Mynda, mencionando questões como a violência que, de certo modo, exaltam e reforçam a centralidade da resistência e do empoderamento nas suas produções artísticas, bem como se relacionam com a questão da maternidade e revelam dimensões sociais, pois a artista refere: Ele apontava o dedo e eu ia perdendo a minha liberdadel Da minha vida nada sabiam/ Pura realidadel Até que vos espetei na cara um teste de paternidade e ainda, Fantasias de amor que foram pura maldade (Lendária, Diz-me Lá, Independente, 2019). Para Lendária, a temática da afirmação vai além da afirmação artística, fazendo menção à sua afirmação enquanto mulher, mas também às vicissitudes que estas enfrentam.

\begin{abstract}
Não sou o que queres/ Não sou o que pensas/Não sou o que vês/ Não sou o que inventas (...) eu sou mulher/ Eu sou cicatrizes/Eu sou lendária, e tu és quem?, bem como Porque eu venço em tudo o que faço/ Sem nunca largar o traço (Lendária, Diz-me Lá, Independente, 2019).
\end{abstract}

Por fim, resta-nos Capicua ${ }^{31}$, nome artístico de Ana Matos Fernandes. Primeiramente, o motivo pelo qual inicialmente a comparamos à Dama Bete, foi pelo facto de esta possuir um contrato com a Universal e além disso fez um sucesso enorme com a música Vayorken (2014), bem como já participou em inúmeros projetos de sucesso, tal como o Língua Franca ${ }^{32}$. A artista é feminista e assume que as suas músicas são uma forma de luta e de resistência contra o patriarcado, contra o machismo e, acima de tudo, servem o propósito de conferir o empoderamento às mulheres. Capicua é doutorada em Geografia Humana e Licenciada em Sociologia. A música que escolhemos para analisar é do seu mais recente álbum, intitulado Madrepérola (2020), álbum esse que é uma ode ao feminismo, à emancipação e à maternidade. A música intitula-se Gaudi $i^{33}$.

Figura 6 - Frames do videoclipe Gaudi, de Capicua

\footnotetext{
${ }^{31}$ Consultar este link: http://www.capicua.pt/capicua

32 Projeto artístico que resulta da junção de quatro $\mathrm{MCs}$, dois brasileiros e dois portugueses, nomeadamente Emicida, Rael, Valete e Capicua.

${ }^{33}$ Disponível em: https://www.youtube.com/watch?v=bA0WMHjkIbo
} 


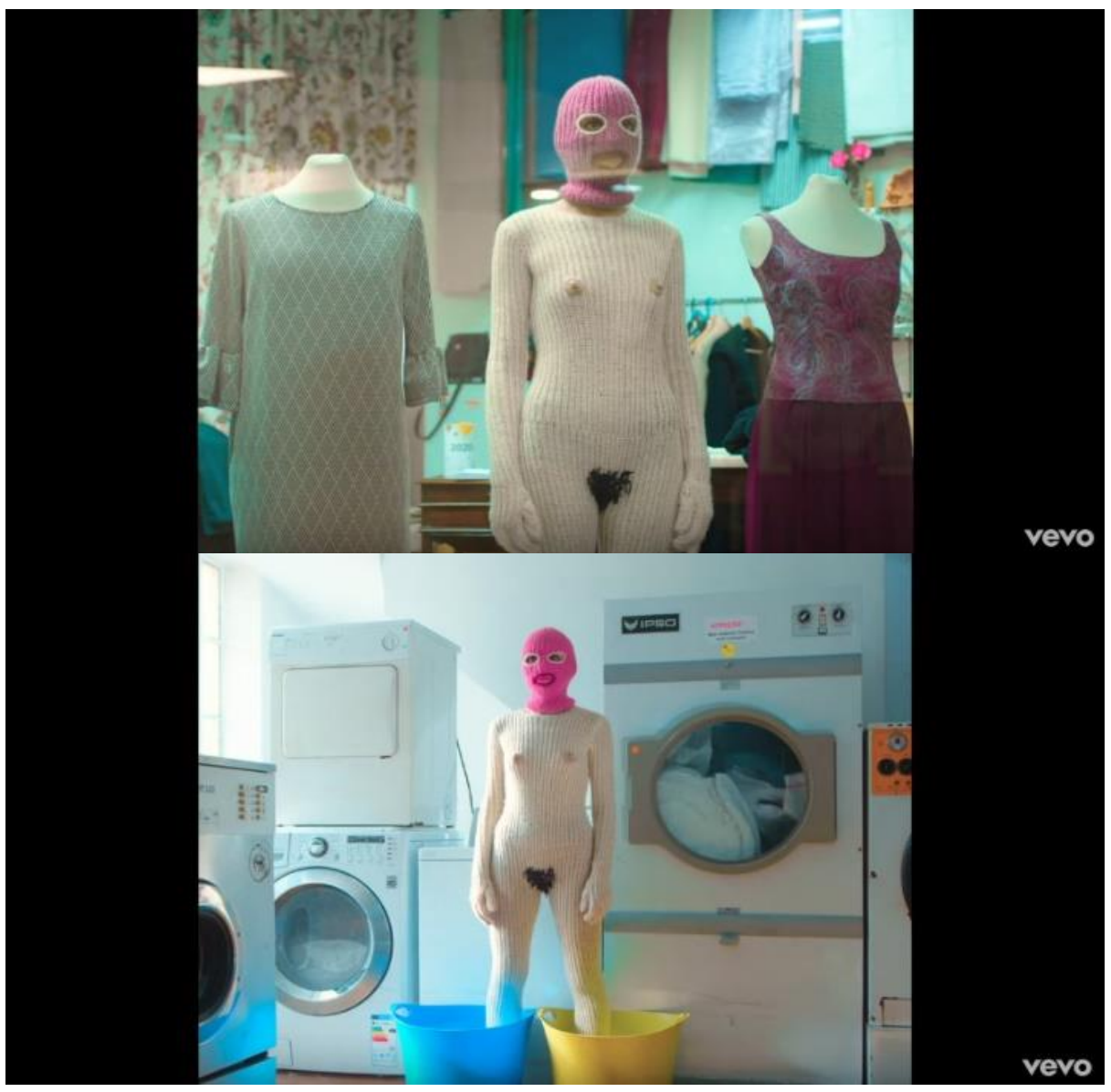

Fonte: Fonte: Capicua, “Gaudi”, Universal, 2020.

Essa música de Capicua aborda um conjunto de problemas que são específicos às mulheres como um todo, não se focando apenas nas mulheres artistas e que se encontram inseridas na cultura hip-hop e, nesse sentido, verificamos de forma sistemática os contributos e as afirmações de Becker (2007). No conteúdo desta canção, são retratadas as relações amorosas, os estereótipos e as discriminações em relação ao corpo, ao trabalho, ou até mesmo às ideias pré-concebidas que são fomentadas face ao papel que a mulher deve ocupar na sociedade (Love, 2012). Tenhamos como exemplo os seguintes excertos: Que estás farta das humilhações/ Do fracasso das relações/ De conselhos e sugestões / bom senso e boas intenções, e temos ainda outro exemplo, Do teu saldo, do teu salto/Porque o saldo é sempre baixo/ E o teu salto é muito alto (Capicua, Gaudi, Universal, 2020).

Este álbum, Madrepérola, lançado em 2020 foi feito como uma ode ao feminismo e à maternidade, visto que a artista tinha sido mãe recentemente, contudo, o mesmo não possuiu a mesma adesão mediática que os seus álbuns anteriores. A sua imagem de rapper militante, emotiva e politicamente envolvida, também se encontra 
explícita no videoclipe, sendo enfatizada a questão do corpo feminino, como podemos ver nos frames acima apresentados (ver Figura 6). Além disso, também importa destacar como o corpo da mulher é representado através do fato, nas imagens. Estas imagens e os discursos assumem-se como uma forma de resistência a todas as normas que são impostas às mulheres e que, na sua essência, acabam também elas por condicionarem a sua entrada no mundo do hip-hop visto que, como já temos vindo a mencionar, o corpo é um eixo central para a indústria musical. A título exemplificativo: Porque há brunche sumos detox/Laser e botox/ Porque há secas/ E dietas e profetas e bogs mas também, Tu estás farta/ Farta, farta até de ti (Capicua, Gaudi, Universal, 2020).

Paralelamente a estas problemáticas que são abordadas pela artista, ela faz uma analogia com uma obra de arte, com um Gaudi. A mesma fala: Eu vou colar esses caquinhos/ E fazer um Gaudi (Capicua, Gaudi, Universal, 2020) ou ainda Se este mundo é surreal/ Bora fazer um Dali, fazendo referência ao empoderamento feminino e à afirmação, ou seja, utilizar todos estes pontos e exigências que são feitas às mulheres, por parte das sociedades em que vivemos, para criar uma obra de arte. No fundo, tratase da exaltação da condição de mulher, ao mesmo tempo que promove o amor próprio, o empoderamento e a afirmação identitária, tenhamos em linha de conta o seguinte excerto, Farta de clichês/ De guichês/ De porquês/ Farta de tirar a senha/ E esperar pelo fim do mês!/ Estás de coração partido/ Ego ferido, já vi (Capicua, Gaudi, Universal, 2020).

Regressando à nossa premissa inicial, consideramos que as práticas artísticas analisadas e apresentadas para este texto - no que se refere às letras das músicas e aos videoclipes das artistas - conferem perspetivas sobre a sociedade portuguesa, no sentido em que consideramos que a música, neste caso concreto o rap, é um princípio essencial para compreendermos as identidades nacionais e locais (Hoeven et al, 2016). O rap foi por nós entendido como um momento e uma prática cruciais para tentarmos entender alguns momentos e vivências chave das artistas, de modo a obtermos uma visão artística e sociológica mais detalhada sobre este gênero musical e os seus modos de relação com a sociedade e com o mundo.

\section{Pistas conclusivas}

Na maioria dos países do Norte Global, mas especialmente em Portugal, a problemática dos discursos - especialmente as letras das músicas e os videoclipes - das 
mulheres inseridas no mundo d hip-hop, têm sido amplamente descartados, não só pelas indústrias culturais, como também pela academia. O movimento hip-hop, foi um dos primeiros a ser alvo de análise, especialmente pelo seu caráter contestatário (Campos \& Simões, 2014; García \& Pàmplos, 2020; Librado, 2010; Simões, 2019), seguindo-se sucessivamente, à medida que a sociedade ia evoluindo, os estudos relacionados com as representações das mulheres (Tavares, 2012, 2010), as referências à violência e a representação de contextos desfavorecidos, mas também se destacam análises sobre o hip-hop enquanto movimento revolucionário e político (García \& Pàmpols, 2020).

Assim, os discursos das mulheres no mundo do rap começam a ganhar força com os estudos que foram surgindo no âmbito do Sul Global (Mazer et al., 2018), nos quais se evidencia um crescimento de grupos artísticos femininos, política e socialmente envolvidos e que utilizam a expressão e a criação artística como um meio de denúncia. No caso português, encaramos estas artistas e as suas músicas e videoclipes, como uma forma destas retratarem a sociedade portuguesa, trata-se assim de uma espécie de protesto gentil e silencioso (Corbett, 2018), que vem evidenciar e acentuar ainda mais a necessidade de se repensar os discursos das mulheres inseridas no mundo do hip-hop, mais concretamente no rap.

Não se trata de enaltecer o empoderamento feminino apenas porque sim. Tratase de analisar e de dar a conhecer as narrativas femininas e as suas literacias (Richardson, 2013) e, essencialmente reconhecer que através dos discursos artísticos, das sonoridades, das mensagens que são transmitidas pelos videoclipes e pelos conteúdos das suas músicas, estas mulheres nos conferem novas tipologias de conhecimento sobre a sociedade. Apesar de não existirem linha retas nem ligações óbvias, devemos recusar expressões e explicações dialéticas e singulares quando o que se pretende é capturar a complexidade sociedade portuguesa (Guerra, 2019). Neste sentido, esta análise procurou distanciar-se das temáticas convencionais abordadas quando pensamos nos movimentos hip-hop e no rap.

\section{Referências}

ANDERSON, M.W. Cities inside Out: Race, Poverty, and Exclusion at the Urban Fringe. Heinonline. 2007. Disponível em:

<https://heinonline.org/HOL/LandingPage?handle=hein.journals/uclalr55\&div=34\&id= \&page $=>$ Acesso em nov. 2021 
ATERIANUS-OWANGA, A. “Tu t'en es pris à la mauvaise go!” Transgressing Gender Norms on the Gabonese Rap Scene. Ethnologie Française, 161, 1, 45-58, 2016.

AUGÉ, M. Não Lugares. Introdução A Uma Antropologia Da Supermodernidade. Lisboa: Papirus, 1994

BALESTRINI, N. The Intermedial Poetry of Rap: Words, Sounds, and Music Videos. In D. Kerler \& T. Müller (Ed.). Poem Unlimited: New Perspectives on Poetry and Genre (pp. 239-254). Berlin, Boston: De Gruyter, 2019

BECKER, H.S Telling about society. Chicago: The University of Chicago Press, 2007

BENNETT, A. \& Guerra, P. DIY Cultures and Underground Music Scenes. London: Routledge, 2018.

BERGGREN, K. Reading Rap: Feminist Interventions in Men and Masculinity Research. PhD Thesis. Uppsala University: Faculty of Social Sciences, 2014.

BERRY, T. V. Female images and roles in music. In A. Kesselman, L. D. McNair, \& N. Schniedewind (Eds.). Women, images and realities: A multicultural anthology, 3rd ed. (pp. 103, 105-106), 2003. Boston MA/New York, NY: McGraw Hill.

CAMPOS, R. \& SIMÕES, J.A. Digital Participation at the Margins: Online Circuits of Rap Music by Portuguese Afro-Descendant Youth. Young, 22, 1, 87-106, 2014.

CHANEY, C. \& BROWN, A. Is Black Motherhood A Marker of Oppression or empowerment? Hip-Hop and R\&B Lessons about "Mama". The Journal of Hip-Hop Studies, 2, 1, 2015.

Disponível em: https://scholarscompass.vcu.edu/jhhs/vol2/iss 1/16/

CORBETT, S. How to be a Craftivist. The art of Gentle Protest. Reino Unido: Rndom House, 2018.

DURHAM, A.; Cooper, B.C. \& Morris, S.M The Stage Hip-Hop Feminism Built: A New Directions Essay. Signs, 38, 3, 712-737, 2013.

FARRUGIA, R. \& HAY, K. Women Rapping Revolution: Hip Hop and Community Building in Detroit. Berkeley: University of California Press.

FORMAN, M. \& NEAL, Mark Anthony (Eds). That's The Joint! The Hip-Hop Studies Reader. New York: Routledge, 2020.

FORMAN, M. (2002). The hood comes first: Race, space, and place in rap and hiphop. Middletown: Wesleyan University Press, 2002.

FRITH, S., \& MCROBBIE, A. Rock and sexuality. In S. Frith \& A. Goodwin (Eds.). On record: Rock, pop and the written word (pp. 317-329). New York, NY: Taylor \& Francis Group, 2005. 
GARCÍA, J.S. \& PÁMPOLS, C.F. In My Name and the Name of All People Who Live in Misery: Rap in the Wake of Revolution in tunisia and Egypt. Young, 28, 1, 85-100, 2020.

GUERRA, P. Cidade, pedagogia e rap. Quaestio - Revista de Estudos em Educação, 22, 2, 431-453, 2020.

GUERRA, P. \& FIGUEIREDO, H.G. Today Your Style, Tomorrow The World: punk, fashion and visual imaginary. ModaPalavra, Florianópolis. Dossiê Moda, Arte e Design. 12, 33, 112-147, 2020.

GUERRA, P. \& SITOE, T. Ritmo, Palavra e Poesia. In T. Sitoe \& P.Guerra (Eds.). Reinventar o discurso e o palco. O rap, entre saberes locais e saberes globais (pp.1627). Universidade do Porto. Faculdade de Letras, Porto, Portugal, 2019.

GUERRA, P. \& MENEZES, P.M. Dias de insurreição em busca do sublime: as cenas punk portuguesas e brasileiras. Revista Sociedade e Estado, 34, 2, 485-512, $2019 .$.

GUERRA, P.; GELAIN, G. \& MOREIRA, T. Collants, correntes e batons: gênero e diferença na cultura punk em Portugal e no Brasil. Lectora, 23, 13-34., 2017.

GUERRA, P. Nothing is forever: um ensaio sobre as artes urbanas de Miguel Januário \pm MaisMenos \pm . Horizonte Antropológico, 25, 55, 19-49., 2019.

HALL, S. (Ed.) Culture, media and identities. Maidenhead: Open University Press, 1997.

HARKNESS, G. True School: Situational Authenticity in Chicago's Hip-Hop Underground. Cultural Sociology, 6, 3, 283-298, 2011..

HERD, D. Conflicting Paradigms on Gender and Sexuality in Rap Music: A Systematic Review. Sexuality \& Culture, 19, 577-589, $2015 .$.

HOBSON, J., \& Bartlow, R. D. Introduction: Representin': Women, hip-hop, and popular music. Meridians: Feminism, Race, Transnationalism, 8, 1, 1-14, 2008.

HOLSTON, J. Insurgent Citizenship in an Era of Global Urban Peripheries. City \& Society, 21, 2, 245-267, 2009.

HOEVEN, A.v.d.; Janssen, S. \& Driessen, S. Articulations of identity and Distinction: the Meanings of Language in Dutch Popular Music. Popular Music and Society, 39, 1, 43-58, 2016.

HUNTER, M. Shake it, shake it: Consumption and the new Gender Relation in hip hop. Sociological Perspectives, 54, 1, 15-36, 2011.

HUNTER, M. \& SOTO, K. Women of Color in Hip-Hop: The Pornographic Gaze. Race, Gender \& Class, 16, 1-2, 170-191, 2009.

KEARNEY, M. C Productive Spaces. Girls' bedroom as sites of cultural production. Journal of Children and Media, 1(2), 126-141, 2007. 
LIBRADO, D. An Instrument of Resistance: Rap Music and Hip-Hop culture in El Alto, Bolivia. Dissertação (Licenciatura). University of Toronto at Scarborough, 2010.

LOVE, B. Hip Hop's Li'l Sistas Speak: Negotiating Hip Hop Identities and Politics in the New South. New York: Peter Lang Publishing, 2012.

MALCOMSON, H. Contesting Resistance, Protesting Violence. Music and Arts in Action, 7, 1, 46-63, 2019.

MARTINS, A. \& GUERRA, P. Rock in high heels: a look through the women's role in Portuguese rock music. In Guerra, P. \& Moreira, T. (Eds). Keep it simple, make it fast! : an approach to underground music scenes. Volume 4 (pp.477-486). Porto: Faculdade de Letras da Universidade do Porto, 2019.

MATSUNAGA, P.A. As representações sociais da mulher no movimento hip-hop. Psicologia \& Sociedade, 20, 1, 108-116, 2008.

MAZER, D.; GELAIN, G. \& GUERRA, P. Eu sou MC: Participação coletiva e plural de mulheres em cenas musicais Rap. In Livro de Atas do II Seminário Internacional de Pesquisas em Midiatização e Processos Sociais, 2018. Disponível em:

https://sigarra.up.pt/fpceup/pt/pub_geral.pub_view?pi_pub_base_id=281910

MCROBBIE, A., \& GARBER, J. Girls and subcultures. In S. Hall \& T. Jefferson (Eds). Resistance through rituals: Youth subcultures in post-war Britain (pp. 209-222).

London: Hutchinson; Birmingham: The Center of Contemporary Cultural Studies from the University of Birmingham, 1975.

MOHAMMED-BAKSH, S. \& CALLISON, C. Hegemonic Masculinity in Hip-Hop Music? Difference in Brand Mention in Rap Music Based on the Rapper's Gender. Journal of Promotion Management, 21, 3, 351-370, 2015.

MORAD, M. Negro Soy Yo: hip hop and raced citizenship in neoliberal Cuba. Ethnic and Racial Studies, 41, 13, 2379-2382, 2018.

MOURA, T. \& CERDEIRA, L. Re-Thinking Gender, Artivism and Choices. Cultures of Equality Emerging From Urban Peripheries, 2021. Frontiers of Sociology.

Disponível em:

https://www.frontiersin.org/articles/10.3389/fsoc.2021.637564/full?\&utm_source=Emai 1_to_authors_\&utm_medium=Email\&utm_content=T1_11.5e1_author\&utm_campaign =Email_publication\&field=\&journalName=Frontiers_in_Sociology\&id=637564

NIETO-ÁLVARO, R. The linguistic path of 'romance': A systemic-functional analysis and gender comparison of songs of the 1950s and the 2000s. Investigaciones FEMINISTAS, 3, 7-22, 2012.

OLIVEIRA, A.A.R.S. Mulheres do rap: uma antropologia compartilhada sobre agências, performances e identidades nas periferias Brasília. Dissertação (Bacharel). Universidade de Brasília: Instituto de Ciências Sociais/ICS e Departamento de Antropologia/DAN, 2018.

ORANGE, C. Rap Videos: A Source of Undesirable Vicarious Empowerment for African-American Males. The Hight School Journal, 79, 4, 281-292, 1996. 
O'TOOLE, C.J. The View from Below: Developing a Knowledge Base About an Unknown Population. Sexuality and Desability, 18, 207-224, 2000.

OWARE, M. Brotherly Love: Homosociality and Black Masculinity in Gangsta Rap Music. Journal of African American Studies, 15, 22-39, 2011.

PRETORIUS, L. The participation of women in rap music: An exploratory study of the role of gender discrimination. Thesis. University of the Western Cape, 2001.

PEDDIE, I. The Resisting Muse: Popular Music and Social Protest. London: Routledge, 2006.

POUGH, G. Women, hip-hop, and a feminist agenda. Black Women, Gender, and Families, 1, 2, 78-99, 2007.

POUGH, G. Check it While I wreck it. Lebanon NH: University Press of New England, 2004.

RÉMY, J. \& VOYÈ, L. A Cidade: Rumo a Uma Nova Definição. Porto: Edições Afrontamento, 1994.

Richardson, E. Developing Critical Hip Hop Feminist Literacies: Centrality and Subversion of Sexuality in the Lives of Black Girls. Equity \& Excellence in Education, 46, 3, 327-341, 2013.

ROSE, R.B. Feminism, Women and the French Revolution. Australian Journal of Politics \& History, 40, 1, 173-186, 1994..

SAID, E. W. Orientalism. Nova Iorque: Pantheon Books, 1979.

SALVATIERRA, C.D. Feminismos activistas en el rap latino-americano: Mare (Advertencia Lirika) y Caye Cayejera. Ambigua, Revista de Investigaciones sobre Gênero y Estudios Culturales, 3, 39-57, 2016.

SAMICO, S. Lideranças femininas e feministas: um estudo sobre a participação de jovens mulheres no movimento hip-hop. Dissertação (Mestrado). Recife: Universidade Federal de Pernambuco, 2013.

SHELTON, M.L. (Can't touch this! representations of the African American female body in urban rap videos. Popular Music \& Society, 21, 3, 107-116, 1997.

SILVA, A.S.; Guerra, P. \& Santos, H. When art meets crisis. The Portuguese story and beyond. Sociologia, Problemas e Práticas, 86, 27-43, 2018.

SIMÕES, S. Para uma história e teoria crítica do RAP em Portugal: Fixar os paradoxos, os caminhos percorridos e as resistências das primeiras mulheres. In T. Sitoe \& P.Guerra (Eds.). Reinventar o discurso e o palco. O rap, entre saberes locais e saberes globais (pp.190-201). Universidade do Porto. Faculdade de Letras, Porto, Portugal, 2019. 
SIMÕES, J.A.V; NUNES, P.B \& CAMPOS, R.M.O. Entre subculturas e neotribos: propostas de análise dos circuitos culturais juvenis. O caso da música rap e do hip-hop em Portugal. Forum Sociológico, 13/14, 2, 171-189, 2005.

SITOE, T. \& GUERRA, P. Reinventar o discurso e o palco. O rap, entre saberes locais e saberes globais. Universidade do Porto. Faculdade de Letras, Porto, Portugal, 2019.

SKEGGS, B. Two Minute brother: Contestation through gender, 'race' and sexuality. Innovation: The European Journal of Social Science Research, 6, 3, 299-322, 2012.

SOJA, E. Six Discourses on the Postmetropolis, 2010. Disponível em:

http://www.opaa2a.org/dissensus/wpcontent/uploads/2008/05/soja_edward_w_six_disc ourses_on_the_postmetropolis.pdf

SOUSA, S. \& GUERRA, P. Toda a minha vida fui Thug. Percursos analíticos sobre o artista gangster e contextos urbanos. Cidades, Comunidades e Territórios, 2021. (no prelo).

TAVARES, B. Música popular rap: a rima da guerreira. Latitude, 6, 1, 83-104, 2012.

Tavares, B. Geração hip-hop e a construção do imaginário na periferia do Distrito Federal. Revista Sociedade e Estado, 25, 2, 309-327, 2010.

WELLER, V. A presença feminina nas (sub)culturas juvenis: a arte de se tornar visível. Revista Estudos Feministas, 13(1), 216, 107-126, 2005.

WHITE, T.R. Missy “Misdemeanor” Elliott and Nicki Minaj: Fashionistin’ Black Female Sexuality in Hip-Hop Culture-Girl Power or Overpowered? Journal of Black Studies, 44, 6, 607-626, 2013.

Data de submissão: 15 de julho de 2020

Data de publicação: 20 de dezembro de 2021 